This item was submitted to Loughborough's Research Repository by the author.

Items in Figshare are protected by copyright, with all rights reserved, unless otherwise indicated.

\title{
Transdermal drug delivery by coated microneedles : geometry effects on effective skin thickness and drug permeability
}

PLEASE CITE THE PUBLISHED VERSION

\section{PUBLISHER}

Elsevier Ltd (@ The Institution of Chemical Engineers)

\section{VERSION}

AM (Accepted Manuscript)

\section{LICENCE}

CC BY-NC-ND 4.0

\section{REPOSITORY RECORD}

Davidson, Adam, Barrak Al-Qallaf, and Diganta Bhusan Das. 2009. "Transdermal Drug Delivery by Coated Microneedles : Geometry Effects on Effective Skin Thickness and Drug Permeability”. figshare. https://hdl.handle.net/2134/4086. 


\title{
Transdermal Drug Delivery by Coated Microneedles: \\ Geometry Effects on Effective Skin Thickness and Drug Permeability
}

\author{
Adam Davidson ${ }^{1}$, Barrak Al-Qallaf ${ }^{2}$, Diganta Bhusan Das ${ }^{3, *}$ \\ ${ }^{1}$ Department of Chemical Engineering, University of Bath, Bath BA2 7AY, UK \\ ${ }^{2}$ Department of Engineering Science, Oxford University, Oxford OX1 3PG, UK \\ ${ }^{3}$ Department of Chemical Engineering, Loughborough University. Loughborough LE11 3TU, \\ UK
}

Accepted for Publication in the journal:

Chemical Engineering Research and Design

July 2008

*Author for correspondence (Email: D.B.Das@lboro.ac.uk;

Tel: 00441509 222509) 


\title{
Transdermal Drug Delivery by Coated Microneedles: Geometry Effects on Effective Skin Thickness and Drug Permeability
}

\section{Adam Davidson ${ }^{1}$, Barrak Al-Qallaf ${ }^{2}$, Diganta Bhusan Das ${ }^{3, *}$}

\author{
${ }^{1}$ Department of Chemical Engineering, University of Bath, Bath BA2 7AY, UK \\ ${ }^{2}$ Department of Engineering Science, Oxford University, Oxford OX1 3PG, UK \\ ${ }^{3}$ Department of Chemical Engineering, Loughborough University. Loughborough LE11 3TU, \\ UK
}

\section{Abstract}

Although transdermal drug delivery has been used for about three decades, the range of therapeutics that are administered this way is limited by the barrier function of the stratum corneum (the top layer of skin). Microneedle arrays have been shown to increase the drug permeability in skin by several orders of magnitude by bypassing the stratum corneum. This can potentially allow the transdermal delivery of many medicaments including large macromolecules that typically cannot diffuse through the skin. This paper addresses the use of microneedles coated with a drug solution film. In particular, we identify how the geometries of various microneedles affect the drug permeability in skin. Effective skin permeability is calculated for a range of microneedle shapes and dimensions in order to identify the most efficient geometry. To calculate effective permeability $\left(\mathrm{P}_{\text {eff }}\right)$, the effective skin thickness $\left(\mathrm{H}_{\text {eff }}\right)$ is calculated. These are then plotted for insulin as a model drug to see how various microneedle parameters affect the profiles of both $\mathrm{H}_{\text {eff }}$ and $\mathrm{P}_{\text {eff. }}$ It is found that the depth of penetration from the microneedle array is the most important factor in determining $\mathrm{P}_{\text {eff, }}$, followed by the microneedle spacings. Other parameters such as microneedle diameter and coating depth are less significant.

Keywords: Effective Skin Permeability, Effective Skin Thickness, Transdermal Drug Delivery, Coated Microneedles

\section{Introduction}

Transdermal drug delivery (TDD) seems to be in clinical use since 1981 (Kumar and Philip, 2007). The first transdermal patch was developed by Alza Corporation as a treatment for motion sickness (Tojo, 1987). Since then, patches have been used in applications such as hormonal therapy, pain relief and as an aid to smoking cessation. Such patches allow the controlled release of drugs over several hours or even days. This is in contrast to bolus drug 
delivery (i.e., administration of a single large dose), such as by use of a hypodermic needle in intravenous delivery whereby the drug is immediately delivered systemically.

Drug delivery via the parenteral route, either by intravenous or intramuscular injection, is particularly common. Injection by hypodermic needle has been 'the gold standard' for drug delivery for over a century (McAllister et al., 2003). But, it has a number of disadvantages associated with it. Hypodermic needles often cause pain, transmit pathogens through needle re-use and require medical expertise to use (Gill and Prausnitz, 2007). Transdermal drug delivery is both painless and user-friendly. Another common method of drug delivery is via the oral route (e.g. taking tablets). However, many drugs such as insulin are severely degraded by digestion processes and as such cannot be administered in an oral formulation (Ito et al., 2006). Drugs administered through TDD avoid gut and first pass liver metabolism, improving drug bioavailability (Xie et al., 2005). However, while TDD offers numerous advantages, its use has been very limited due to the small range of drugs that can be effectively delivered this way. Even though blood circulation is close to the skin surface, the skin is very well adapted to prevent infectious substances entering the body. This is largely due to the outer layer of skin, the stratum corneum. In order to passively diffuse through this layer, drug molecules must be of a low molecular weight $(<500 \mathrm{Da})$ and hydrophobic. Even if these conditions are met, the drug must be potent so that the small amounts that can be delivered are sufficient (Gill and Prausnitz, 2007).

When considering a model for transdermal diffusion, it is usually assumed that the skin acts as a bi-layer membrane which consists of the stratum corneum and the viable skin. Drug that permeates through the viable skin is rapidly absorbed by the microcirculation (Tojo, 1987). It is clear that the stratum corneum is the main barrier to diffusion through the skin. The diffusion coefficient of drug molecules within the stratum corneum is usually at least 500 10,000 times smaller than within the viable skin (Tojo, 1987). In general, there are several ways in which its barrier ability can be reduced or bypassed and hence achieving better transdermal drug delivery. These include electroporation (Sen et al., 2002), phonophoresis (Mitragotri et al., 1995), sonophoresis (Merino et al., 2003) and chemical enhancers (Williams and Barry, 2004). However, the range of drugs that can be incorporated into such drug delivery systems is limited by the barrier function of the skin. The outer layer, or stratum corneum, which is rate-limiting for transdermal transport, has been shown to be the main obstacle for high molecular weight drugs to diffuse through the skin (Badkar et al., 2007). Therefore, most drug molecules with high molecular weight are unable to effectively enter the bloodstream. 
In addition to the methods mentioned previously, skin permeability can also be enhanced through the use of microneedles (Kim and Lee, 2007). Arranged into an array, these are micron-scale projections that penetrate through the stratum corneum, creating a superficial pathway through which drugs can reach the deeper levels of the skin. The working principle of the microneedle arrays has been discussed in a number of previous papers (Prausnitz, 2004; Al-Qallaf et al., 2007). Till date, four methods of transdermal delivery mediated by microneedles have been attempted (Gill and Prausnitz, 2007):

(i) Applying an array of microneedles to first permeabilize the skin before using a traditional transdermal patch.

(ii) Coating the microneedles with a drug containing film before inserting into the skin.

(iii) Creating the microneedles from a polymeric material that contains the drug. The drug is then released in a controlled manner after insertion into the skin.

(iv) Injection through hollow microneedles.

The first three methods utilise solid microneedles and the last method relies on a liquid formulation being injected through hollow microneedles. Hollow microneedles have generally received less attention to date as they are inherently structurally weaker and have practical problems such as the bore hole being clogged by tissue (Wang and Cornwell, 2006). This paper will focus on the second method, the so-called "coat and poke" approach (Prausnitz, 2004) as shown in Figure 1.

Recently, there has been an interest to investigate the influences of a variety of variables related to the microneedles to reach the optimum microneedle design and hence, improve the transdermal drug delivery when using microneedle arrays. Many relevant factors have been considered to formulate an optimized microneedle arrays, including the mask shape of the microneedle (Wilke and Morrissey, 2007), location of the microneedle hole (Khumpuang et al., 2007), the microneedle tip radius (Teo et al., 2006), etc. However, most of these studies made their decision based on different criteria such as microneedle insertion, but not skin permeability, although skin permeability has been considered as a key factor that determines the efficiency of transdermal drug delivery process (Wilke et al., 2006).

Our previous study showed the effect of various parameters (e.g., number of microneedles, microneedle radius, etc) influencing the permeability of skin (Al-Qallaf and Das, 2007). This has been done by developing an optimization algorithm to determine the optimum microneedle dimensions of both hollow and solid microneedles. Skin thickness based on different classifications (e.g., race, sex, etc) has been correlated with skin permeability (Al- 
Qallaf and Das, 2007). In another study, we proposed a mathematical framework which provides quantitative evaluations of various parameters influencing the drug concentration in blood (Al-Qallaf et al., 2007). A scaling analysis has also been done which describes the functional dependency of drug concentration on other variables of skin and microneedle arrays (Al-Qallaf et al., 2007). Following from these studies, this work aims to quantify the influence of various geometrical parameters (e.g., microneedle thickness, coating depth, etc) associated with six microneedle shapes of coated drugs on the effective skin permeability with a view to identify the most effective geometry of the micro-needles. The ratio $\left(\mathrm{R}_{\mathrm{P}}\right)$ of drug permeability with microneedles to the permeability of normal skin (i.e., without microneedle arrays) has also been determined. This has been done to obtain more information for designing microneedle arrays since that little quantitative research has been presented for determining skin permeability using microneedles (Wu et al., 2006). This ratio helps to assess the ability of increasing skin permeability using microneedles. This parameters seems to be useful to compare various microneedles model, and hence, to achieve the optimum geometry.

\section{Modelling Strategy}

\subsection{Model Assumptions}

For the purpose of this work, the following assumptions are made:

(1) The concentration of the drug $(\mathrm{C})$ in the blood remains low throughout, and so the blood is considered to act as a sink, i.e. $\mathrm{C}=0$ for all time ( $\mathrm{t}$ ).

(2) Skin binding is assumed to be negligible in the viable skin.

(3) Drug metabolism is assumed to be negligible in the viable skin.

(4) All drug molecules that diffuse through the viable skin are taken up by the microcirculation.

(5) The rate limiting step is diffusion through the viable skin.

The first assumption can be considered to be realistic as drug coating solutions are generally many orders of magnitude greater than the drug plasma concentration. Skin binding involves drug molecules becoming bound to active sites on macromolecules, which can cause a reduction of the diffusion coefficient to an 'effective value' that is a function of drug concentration (Tojo, 2005). Drug binding tends to be prevalent in the stratum corneum rather than the viable skin, so ignoring it is a reasonable approximation.

Metabolism by the living cells in the viable skin however can lead to an appreciable decrease in the systemic delivery of the drug (Tojo, 2005). To our best knowledge, there is no data to quantify the effect of skin metabolism on various drugs, particularly for those drugs that have not typically been used in transdermal delivery before. In one study, the pharmacological availability of insulin delivered by drug-loaded polymer microneedles was found to be 
between $91-98 \%$ when compared to intravenous dosing. In many practical cases, it may be possible to prevent metabolism, as demonstrated by Sintov and Wormser (2007). Iodine was used to deactivate skin glutathione so that insulin could retain its potency as it permeated through. As the objective of this paper is to compare microneedle designs, metabolism of drugs in the viable skin is ignored for simplicity.

The fourth assumption defines that $100 \%$ of the drug molecules that diffuse into the area of skin occupied by the microcirculation (taken to be $200 \mu \mathrm{m}$ deep) are absorbed into the blood. This is a common assumption and is considered realistic (see, e.g., Tojo, 1987).

The final assumption defines that the rate at which the drug dissolves into the tissue fluids and the rate at which it is absorbed by the blood is rapid compared to the rate at which it diffuses through the viable skin. This is a fair approximation, as the coating should be a mainly aqueous solution and will quickly dissolve into the skin's tissues (i.e., within 20 seconds) according to Gill and Prausnitz (2007). Drug molecules should also be quickly absorbed into the blood, especially in vivo (Tojo, 1987).

\subsubsection{Governing Equations for Drug Transport in Skin}

For solid microneedles coated by an aqueous solution of drug molecules, the rate-limiting step is the transport of drugs through the viable epidermis. Drug molecules dissolve in the interstitial fluids of the skin and diffuse towards the microcirculation in the dermis. It is assumed that absorption by the blood is rapid compared to permeation through the skin (Tojo, 1987). In order to determine the effective skin permeability, and hence, the effective skin thickness, Fick's first law has been adopted:

$$
J=-D \frac{d C}{d x}
$$

Where $\mathrm{J}$ is the flux of drug through the skin, D is the diffusion coefficient of drugs in skin, C is the concentration of diffusing drug and $\frac{d C}{d x}$ is the concentration gradient.

At steady state (i.e. $\frac{\mathrm{dC}}{\mathrm{dt}}=0$ ) it can be defined that,

$$
\frac{\mathrm{dC}}{\mathrm{dx}}=\text { constant }=\frac{\mathrm{C}_{2}-\mathrm{C}_{1}}{\mathrm{H}}
$$

Here, $\mathrm{H}$ is the thickness of the skin after microneedles have been inserted, $\mathrm{C}_{2}$ is drug concentration at the bottom of epidermis layer and $\mathrm{C}_{1}$ is drug concentration at the tip of microneedles. Now, combining Fick's first law (equation 1) with equation (2), we obtain an expression for steady state diffusive flux $\mathrm{J}_{\mathrm{Ss}}$ as follows: 


$$
\begin{aligned}
& \mathrm{J}_{\mathrm{ss}}=-\frac{\mathrm{D}}{\mathrm{H}}\left(\mathrm{C}_{2}-\mathrm{C}_{1}\right) \\
& \mathrm{J}_{\mathrm{ss}}=-\mathrm{P}\left(\mathrm{C}_{2}-\mathrm{C}_{1}\right)
\end{aligned}
$$

Where $\mathrm{P}$ is the drug permeability in skin. When $\mathrm{C}_{2}$ is defined to be zero (i.e., sink condition) $\mathrm{J}_{\mathrm{ss}}$ is given by:

$$
\mathrm{J}_{\mathrm{ss}}=\mathrm{PC}_{1}
$$

For coated microneedles, the drug permeability is increased by bypassing the stratum corneum. This leaves the drug to diffuse across the viable skin (which consists of the viable epidermis and dermis) into the blood microcirculation. Assuming steady state transport across skin (Park et al., 2005), the effective permeability $\mathrm{P}_{\text {eff }}$ of the skin when coated microneedles are being used is calculated by:

$$
\mathrm{P}_{\mathrm{eff}}=\frac{\mathrm{D}_{\mathrm{vs}}}{\mathrm{H}_{\mathrm{eff}}}
$$

Where $D_{v s}$ is the diffusion coefficient of the drug in the viable skin which is assumed to be constant (i.e., the diffusion coefficients in the viable epidermis and dermis are of the same magnitude) (Tojo, 1987) and $\mathrm{H}_{\text {eff }}$ is the effective thickness of the skin after microneedles have been inserted. Therefore, $\mathrm{H}_{\mathrm{eff}}$ is a function of purely of microneedle geometry.

\subsubsection{Skin Permeability (without microneedles arrays)}

The effective permeability of a drug due to microneedles can be compared with its permeability through normal skin that has its stratum corneum intact. By considering the skin to act as a bilayer membrane (Tojo, 1987), the permeability of intact skin is found by reciprocal addition of the permeability of the two layers, the stratum corneum and viable skin as follows:

$$
\begin{aligned}
& \mathrm{R}=\frac{1}{\mathrm{P}_{\text {skin }}}=\frac{1}{\mathrm{P}_{\mathrm{sc}}}+\frac{1}{\mathrm{P}_{\mathrm{vs}}} \\
& \mathrm{P}_{\text {skin }}=\frac{\mathrm{D}_{\mathrm{sc}} \times \mathrm{D}_{\mathrm{vs}}}{\mathrm{D}_{\mathrm{sc}} \times \mathrm{H}_{\mathrm{vs}}+\mathrm{D}_{\mathrm{vs}} \times \mathrm{H}_{\mathrm{sc}}}
\end{aligned}
$$

Where $\mathrm{R}$ is the resistance, $\mathrm{P}_{\text {skin }}$ is skin permeability, $\mathrm{D}_{\mathrm{sc}}$ and $\mathrm{D}_{\mathrm{vs}}$ are diffusion coefficients of stratum corneum and viable skin, respectively while $\mathrm{H}_{\mathrm{sc}}$ and $\mathrm{H}_{\mathrm{vs}}$ are thicknesses of stratum corneum and viable skin, respectively. The resistance implies the inverse of permeability.

The ratio $\left(\mathrm{R}_{\mathrm{P}}\right)$ of permeability with microneedles to the permeability of normal skin is given by dividing equation (8) by equation (6) as follows: 


$$
\mathrm{R}_{\mathrm{p}}=\frac{\mathrm{H}_{\mathrm{vs}}+\mathrm{R}_{\mathrm{D}} \times \mathrm{H}_{\mathrm{sc}}}{\mathrm{H}_{\mathrm{eff}}}
$$

Where, $R_{D}$ is the ratio of diffusion coefficients in the viable skin and stratum corneum. This value is typically $500-10,000$ (Tojo, 1987).

\subsection{Microneedles Models}

For the purpose of this work, six microneedle shapes have been chosen, as shown in Table 1 and Figure 2. The shapes have been chosen according to what has been seen in literature, although the exact dimensions are not the same. Microneedle model A consists of a cylindrical shaft with a cone tip. Needles of this form have been constructed by Xie et al. (2005). The standard dimensions are shown in Figure 2(A). Whenever the dimensions are varied, the tip angle is maintained at $45^{\circ}$. Microneedle model B is a cone shape. An example of this type of needle can be seen in Figure 2(B), fabricated by Henry et al. (1998). As the geometry is varied, the tip angle is maintained at $79.9^{\circ}$. Microneedle model $\mathrm{C}$ is a cylinder with a bevelled tip. An example of such a microneedle is shown in Figure 2(C), fabricated by McAllister et al. (2003). The standard dimensions are also shown. As the geometry is varied, the bevel angle of $45^{\circ}$ is maintained. Microneedle model D is shown in Figure 2(D) with its standard dimensions, along with an example of this type of needle from Gill and Prausnitz (2007). The tip angle is maintained at $45^{\circ}$. Microneedle model $\mathrm{E}$ is an 'arrow-head' type needle manufactured by Gill and Prausnitz (2007) as shown in Figure 2(E). The arrow-head length and tip angle of $53.1^{\circ}$ is maintained as the microneedle geometry is varied. Microneedle model F is a triangular type microneedle proposed by Martanto et al. (2004) as shown in Figure 2(F). The tip angle is maintained at $79.9^{\circ}$ as the geometry is varied.

\subsection{Method of solution}

Drug diffusion from coated microneedles is modelled in 3D using FEMLAB, a piece of scientific modelling software from Comsol (Comsol, 2005). It allows equation-based multiphysics modelling in an interactive environment. Free-form partial differential equations can be set up or particular physics applications can be chosen, in this case diffusion. 3D geometry of the microneedles can then be drawn and the diffusion of drug molecules analysed in transient or steady state. This is done by performing finite element analysis on the domain of interest. The domain is discretised into a mesh of small 3D elements, usually tetrahedrons. Our results show that the mesh is accurate enough, so that refining it did not significantly change the results. Boundary conditions and subdomains parameters are set and the PDE's that characterise the physics of the domain are converted into ordinary differential equations. 
In order to model the diffusion process from the coated microneedles into the skin, the diffusion model was used in FEMLAB as shown in Figure 3 where the standard dimensions for the FEMLAB model, in this case are microneedle model A. CD is the coating depth of drug on the microneedle (i.e., the distance from the tip that is coated by the drug film). As a standard, this is $100 \mu \mathrm{m}$, as seen in literature (Widera et al., 2006). S is the width and length 250 of the square element of skin. It also represents the centre-to-centre spacing of the microneedles, assuming they are in a square pattern. As a standard, this distance was $100 \mu \mathrm{m}$. The distance to the microcirculation from the skin surface has been reported as $200 \mu \mathrm{m}$ (Tojo, 1987) and so that is used here. Similarly other models were also set up based on Table 1 and Figure 2.

The skin is modelled as a single subdomain with an isotropic diffusion coefficient (D). It was found that having a layer to represent the stratum corneum did not significantly affect the results and so it is not included in the model for simplicity. The blood is assumed to act as a sink for the drug and so this boundary condition is set (concentration is set to zero on this boundary).

The boundary conditions for the drug concentration at the surface of the coated microneedle are,

$$
\mathrm{C}=\mathrm{C}_{\mathrm{a}} \text { at } \mathrm{L}_{\mathrm{u}}<\mathrm{x}<\mathrm{L} \text { for } \mathrm{t}>0
$$

On the other hand, the boundary condition for the drug concentration at the bottom of the epidermis layer is,

$$
\mathrm{C}=0 \quad \text { at } \quad \mathrm{x}=\mathrm{h} \quad \text { for } \mathrm{t}>0
$$

Where $\mathrm{C}_{\mathrm{a}}$ is the drug concentration at the surface of the coated drug, $\mathrm{L}_{\mathrm{u}}$ is the uncoated microneedle length, $\mathrm{L}$ is the microneedle length, $\mathrm{h}$ is the epidermis thickness (i.e. equal to 200 $\mu \mathrm{m}), \mathrm{x}$ is the distance in a given skin layer and $\mathrm{t}$ is time.

We calculate the steady state diffusive flux of drug through the blood interface assuming the concentration of drug on the needle is constant. It allows the calculation of effective skin thickness $\mathrm{H}_{\text {eff, }}$ which is purely dependent on microneedle geometry. In our approach, $\mathrm{H}_{\text {eff }}$ is calculated using the following method. The flux term determined from the simulations is integrated over the microcirculation boundary and then divided by the boundary area to give an average steady state flux, $\mathrm{J}_{\mathrm{ss}}$. By rearranging the steady state of Fick's first law, the following expression is found:

$$
\mathrm{H}_{\mathrm{eff}}=\frac{\mathrm{D}_{\mathrm{vs}} \times \mathrm{C}_{\mathrm{a}}}{\mathrm{J}_{\mathrm{ss}}}
$$


Where $\mathrm{C}_{\mathrm{a}}$ is the drug concentration at the surface area of the coated drug and $\mathrm{H}_{\text {eff }}$ can then be used to calculate the effective skin permeability $\mathrm{P}_{\text {eff }}$ in equation (6). It is assumed that the drug concentration at the surface area of the coated drug is $1 \%(\mathrm{w} / \mathrm{v})$, which is $1 \mathrm{~g} / 100 \mathrm{ml}$. This is a typical value from the work by Gill and Prausnitz (2007). This value was kept the same in all cases.

By symmetry, it is possible to model a whole array of microneedles by modelling only a single microneedle. For instance, it can be shown that the flux of drug from one microneedle only needs to be multiplied by the number of microneedles in the array to give the total flux of drug. For example, an array of nine microneedles can be represented by the modelling a single microneedle, due to symmetry. This is convenient as the geometry of the problem becomes considerably simpler. 3D modelling of complex geometry requires greater computer processing power and takes longer simulation time.

\section{Results and Analyses}

In the present work, the following geometrical parameters of the microneedles were varied: depth of penetration, diameter (microneedle models $\mathrm{A}$ and $\mathrm{C}$ ), thickness (microneedle models $\mathrm{D}$ and E), coating depth, center-to-center spacing. In addition, hexagonal symmetrical elements were designed for microneedle models A and B to compare with the case of square elements. Skin is wrinkled and has various surface features such as hairs. In addition to the visco-elasticity of the skin, this means that microneedles will not penetrate to their full length (McAllister et al., 2003). In general, microneedles longer than $100 \mu \mathrm{m}$ should be used to ensure that they penetrate beyond the stratum corneum (Stoeber and Liepmann, 2005). As the microcirculation is located $\sim 200 \mu \mathrm{m}$ beneath the skin's surface in general, the microneedles should be shorter than this to prevent any chance of bleeding. For these reasons, the microneedles in the model are varied between 100-180 $\mu \mathrm{m}$. The microneedle diameter ranges from 30-70 $\mu \mathrm{m}$ and the thicknesses between $25-75 \mu \mathrm{m}$. The diameter of microneedle model B was not varied as the tip angle of $79.9^{\circ}$ must be maintained and a change in diameter would not be possible without a change in penetration depth. Coating depth ranges between 40-120 $\mu \mathrm{m}$ and centre-to-centre spacing ranges between $75-200 \mu \mathrm{m}$. These ranges have been chosen based upon typical values seen in literature.

\subsection{Effects of depth of penetration}

The ability of controlling the depth of penetration has a significant limitation when using the microneedles of different geometries (Matriano et al., 2002). It is therefore important to relate microneedle dimensions to the penetration depth which then influence the performance of the 
microneedles for drug delivery process (Teo et al., 2005). Widera et al. (2006) showed that coated microneedles with different drug doses did not decrease the penetration depth for a given microneedle length. However, the depth of penetration decreased with increased microneedles length for a given dose (Widera et al., 2006). In contrast, Cormier et al. (2004) compared the penetration depth for both coated and uncoated microneedles. In their study, they found a significant reduction in penetration depth for coated microneedles.

To address this issue in a systematic manner, the depth of microneedle penetration was varied for all types of microneedle to calculate the effective skin thickness $\mathrm{H}_{\text {eff }}$ and effective skin permeability $\mathrm{P}_{\text {eff }}$ of insulin as a model drug $\left(D_{\mathrm{vs}}=1 \times 10^{-10} \mathrm{~cm}^{2} / \mathrm{s} ; \mathrm{Lv}\right.$ et al., 2006). Microneedle length in this model represents the depth to which the microneedle penetrates the skin, and as such, does not directly represent the physical length of the microneedle. Besides depth of penetration, the standard dimensions in Table 1 are used in all of the microneedle models and the results are shown in Figure 4. There is an obvious linear relationship between $\mathrm{H}_{\text {eff }}$ and microneedle penetration depth for all the models. The data points for both microneedles models $\mathrm{A}$ and $\mathrm{C}$ are indistinguishable due to the similarity in their geometry. For this reason, the data for microneedle model $\mathrm{C}$ is not plotted. The linear result is a consequence of the fact that the average diffusion path length becomes shorter in proportion to the depth of penetration. For a given length, the effective skin permeability is the maximum for microneedle model $\mathrm{D}$ and the minimum for microneedle model $\mathrm{B}$. The geometry of microneedle model $\mathrm{D}$ is such that its tip has a relatively large surface area and thus presents a larger amount of drug closer to the microcirculation. This reduces the effective skin thickness and increases the effective permeability.

\subsection{Effects of microneedle diameter}

Rajaraman and Henderson (2005) argued that the microneedle diameter depends on the materials used for fabrication. The experimental results conducted by Stoeber and Liepmann (2005) illustrated that microneedle diameter depends on the maximum microneedles density (i.e., number of microneedles per unit area). The force needed to cause microneedle failure during piercing through skin increases by increasing microneedle diameter (Park et al., 2007). These results were consistent with the simulations presented by Haider et al. (2001) where the insertion force requirements increased with increasing microneedle diameter. Teo et al. (2005) demonstrated that increasing microneedle diameter improved transdermal drug transport. Microneedles tend to buckle for a given diameter and length by increasing microneedles length but of the same diameter at pressure less than that needed to penetrate the stratum corneum (Mukerjee et al., 2004). Microneedle with larger diameter provides higher 
mechanical stability than that with a smaller diameter (Ovsianikov and Chichkov, 2007). Khumpuang et al. (2005) fabricated microneedles array with a microneedle diameter of 40 $\mu \mathrm{m}$ to prevent any problems appear in blood clogging due to the small diameter of while blood cell (i.e., approximately more than $20 \mu \mathrm{m}$ ).

Following the above discussions, we investigated the influence of various microneedle diameters on both the effective skin thickness and effective skin permeability for various geometries. Figure 5 was obtained when the diameters of microneedles model A and model C were varied. Besides diameter, the other dimensions are standard values (penetration depth $=$ $140 \mu \mathrm{m}$, coating depth $=100 \mu \mathrm{m}$, microneedle spacing $=100 \mu \mathrm{m}$ ). It can be seen in Figure 5 that by increasing the diameter, the effective skin thickness is decreased, increasing the effective skin permeability. However, over the range of diameters tested, the effective skin thickness only changed by less than $10 \%$, indicating the effective skin thickness is not a strong function of the diameter. As the diameter is increased, the diffusion paths from the microneedle to the corners of the microcirculation interface are reduced. This is responsible for decreasing effective skin thickness and increasing effective skin permeability. Diameter may be more important in increasing the available surface area for drug coating on the microneedle. Effective skin permeability appears to tend to a constant value as diameter is increased. For a given diameter, there is little difference in the effective skin permeability when either microneedle is considered. This is presumably due to the similarity of geometry in the two models.

\subsection{Effects of microneedle thickness}

The thickness of microneedle has been considered as an important parameter, since it is related to the length of microneedles and hence its strength (Rajaraman and Henderson, 2005). Davis et al. (2004) found that the force of microneedle fracture depends on the microneedle thickness. They noticed that the margin of safety (i.e., ratio between microneedle fracture and skin insertion force) reached its highest value with large microneedle thickness.

To determine the effects of this parameter, the thickness of microneedle models D-F was varied and the results are shown in Figure 6. Standard dimensions were used in Table 1. The results indicate that by increasing the thickness of these microneedles, effective skin thickness will decrease and permeability will increase. The range of effective skin thickness is quite small for each microneedle (13-15\%) when compared to the range that was obtained by varying length $(>60 \%)$. This indicates effective skin thickness is a relatively weak function of thickness, like diameter. Unlike in the case of diameter though, effective skin permeability appears to be a linear function of thickness. The mechanism by which permeability is 
increased is probably due to the shortening of diffusion paths from the microneedle to the corners of the microcirculation interface in the skin diffusion model.

\subsection{Effects of microneedle drug coating depth}

Gill and Prausnitz (2007) examined the ability of controlling the microneedle length by varying the coverage coating percentage of the microneedle length. However, they did not 395 study the influence of this variation on skin permeability. Widera et al. (2006) studied the effect of changing the coating dose for four microneedle array designs. They found that both the length and density of microneedles did not influence the total amount of drug delivered into the skin. The amount delivered of ovalbumin as a model protein increased as a result of increasing the coating concentration of ovalbumin (Matriano et al., 2002). However, decreasing the coating dose would improve the drug delivery efficiency (Cormier et al., 2004).

In this study, the depth of drug coating was varied on all microneedles (with otherwise standard dimensions), between 40 to $120 \mu \mathrm{m}$. The effect on effective skin thickness and 405 permeability are shown in Figure 7. For all cases, except microneedle model B, effective skin thickness and skin permeability are very weak functions of the coating depth of the drug film on the microneedle. As mentioned before, microneedle model A and microneedle model $\mathrm{C}$ were found to be indistinguishable so microneedle model $\mathrm{C}$ is not plotted. Beyond 60-80 $\mu \mathrm{m}$ it seems that effective skin thickness and effective skin permeability become independent of coating depth. It is difficult to explain why coating depth appears to be more important in determining effective skin permeability for microneedle B than the other models.

\subsection{Effects of microneedle spacing}

As expected, the center-to-center distance between two adjacent microneedles is an important factor for fabricating microneedles (Choi et al., 2006). The insertion force of microneedles depends on microneedles spacing (Parker et al., 2007). This accords well where the insertion force of microneedles depends on microneedles spacing as well as microneedle length (Davis et al., 2004). They suggest that the insertion force depends also on the number of microneedles as long as the spacing is wide enough. Increasing the center-to-center spacing improves the transdermal drug delivery efficiency of coated microneedles (Gill and Prausnitz, 2007). Haider et al. (2001) also demonstrated this by increasing microneedle spacing which reduced penetration force. While the previous studies attempted to determine effects of microneedle spacing on the force of insertion, it not clears how the spacing influences the effective skin permeability and thickness. 
To address this issue in this work, the centre-to-centre spacing was varied between 75-200 $\mu \mathrm{m}$ for all the microneedle models (with standard dimensions). From Figure 8, it appears that an exponential relationship exists between microneedle spacing and both effective skin thickness and effective skin permeability. When each series of data is fitted to an exponential trend line, the $\mathrm{R}^{2}$ value is greater than 0.99 , indicating a strong agreement. As spacing increases, the surface area of the microcirculation interface (where the sink condition exists) in each square symmetrical element of the microneedle array also increases. The diffusion paths from the microneedle surfaces in the centre of the element to the corners of the microcirculation interface become longer as the area of the interface increases. This is responsible for the increase in effective skin thickness and hence the decrease in effective skin permeability. As stated before, the data for microneedle model $\mathrm{C}$ was indistinguishable from microneedle model A and so was not plotted.

\subsection{Square or hexagonal microneedle array pattern}

Since the first fabrication of microneedles, different microneedles array patterns have been proposed such as square (Hsu et al., 2007), hexagonal (Widera et al., 2006), etc. However, the shape of the pattern does not represent the shape of microneedle cross section (Rodriguez et al., 2005). In this work, it was determined whether arranging the microneedles into a hexagonal pattern affected the effective permeability of skin. This was done by using hexagonal shaped elements in the skin diffusion model instead of square ones. Therefore, the demonstration has been done for microneedle models A and D. Figure 9 indicates that for a given centre-to-centre spacing, effective skin permeability is slightly greater when a hexagonal array pattern is used over a square pattern. As mentioned previously, the relation between effective skin thickness and effective skin permeability with microneedle spacing is an exponential increasing and decaying, respectively. For a given centre-to-centre microneedle spacing, the area of the microcirculation interface is greater for square elements. As a result, the diffusion paths are then longer which results in a greater effective skin thickness.

\subsection{Effects of increase in skin permeability relative to untreated skin}

Microneedle arrays have been considered as an intelligent drug delivery devices (Tao and Desai, 2003). Over the past few years, a variety of methods have been proposed to determine the skin permeation of drugs caused by microneedles. Wu et al. (2006) used macroneedles instead of microneedles and determined permeability through treated skin by macroneedles. Wu et al. (2007) compared permeability of high molecular compounds through treated skin by microneedle before and after applying the iontophoresis. This has been done by evaluating permeability factor (i.e., ratio of flux through fresh intact skin over flux post-iontophoresis). 
However, as far as the authors know, no theoretical effort had ever been done for evaluating the relative skin permeability to quantify the changes before and after applying the microneedles across skin. For that reason, we determine the ratio of permeability with microneedles and permeability of normal skin $\left(\mathrm{R}_{\mathrm{P}}\right)$ which is a function of $\mathrm{H}_{\mathrm{eff}}$, the effective skin thickness and $R_{D}$, the ratio of diffusion coefficients in the viable skin and stratum corneum. As mentioned previously, the value of $R_{D}$ varies between $500-10,000$ (Tojo, 1987). The thickness of stratum corneum and viable skin were assumed to be $20 \mu \mathrm{m}$ and $180 \mu \mathrm{m}$, respectively. This has been assumed since that the distance to the microcirculation from the skin surface has been reported as $200 \mu \mathrm{m}$ (Tojo, 1987). Figure 10 shows how $\mathrm{R}_{\mathrm{P}}$ varies as a function of $\mathrm{H}_{\text {eff }}$ for particular values of $\mathrm{R}_{\mathrm{D}}$. The range of $\mathrm{H}_{\mathrm{eff}}$ corresponds to the range calculated in the previous section. The permeability of skin is increased by around 3 orders of magnitude compared to normal untreated skin (i.e., $R_{p}$ ranges from $63-6673$ ). This result is consistent with literature, which states that microneedles can improve skin permeability by over 1000 times when left in place (Henry et al., 1998).

\section{Conclusions}

The geometry effects of various types of solid microneedles with insulin as a model drug have been discussed in this paper. A framework has been presented in this paper to identify the best microneedle models used in transdermal drug delivery to increase skin permeability. Microneedle model $\mathrm{D}$ was the best model in terms of penetration depth, microneedle thickness, coating depth and center-to-center spacing while, microneedle model A was the best model in terms of microneedle diameter. Effective skin thickness $\left(\mathrm{H}_{\mathrm{eff}}\right)$ and permeability $\left(\mathrm{P}_{\text {eff }}\right)$ were calculated for various microneedle models. It was found that microneedle penetration depth was the most significant factor in determining these parameters. This is expected, as deeper microneedle penetration will directly shorten the drug diffusion paths from the microneedle surfaces into the microcirculation of the skin. Centre-to-centre spacing of the microneedles in the array also had a significant effect on effective permeability. The other microneedle dimensions, the diameter in cylindrical needles, the thickness in flat needles, and the coating depths were less significant in determining $\mathrm{P}_{\text {eff. }}$. In general, larger, longer and more densely packed microneedles will result in greater skin permeability, which is an intuitive result. Skin permeability was seen to be enhanced by around 3 orders of magnitude through use of microneedles in the model, which is consistent with practical studies. This suggests that for designing microneedle arrays, considering the geometries of the microneedle arrays enhance efficiency of transdermal drug delivery techniques. The proposed relationship of both effective skin permeability and skin thickness allow us to predict the permeation across human skin and to correlate the microneedles geometries to deliver low/high molecular weight drug using microneedles. Further work should include practical 
experimental data and clinical trials to determine whether the models from this research accurately represent the real situation.

\section{Acknowledgment}

The authors would like to thank MOI (Ministry of Interior), Kuwait for funding this work.

\section{Nomenclature}

C Concentration of diffusing drug (units. $\mathrm{m}^{-3}$ )

$\mathrm{C}_{1} \quad$ Drug concentration at the tip of microneedle (units. $\mathrm{m}^{-3}$ )

$\mathrm{C}_{2} \quad$ Drug concentration at the bottom of epidermis layer (units. $\mathrm{m}^{-3}$ )

$\mathrm{C}_{\mathrm{a}} \quad$ Drug concentration at the surface of the coated drug (units. $\mathrm{m}^{-3}$ )

$\mathrm{CD}$ Coating depth of drug on the microneedles $(\mu \mathrm{m})$

D Diffusion coefficient of drug in skin $\left(\mathrm{m}^{2} . \mathrm{s}^{1}\right)$

$\mathrm{D}_{\mathrm{sc}} \quad$ Diffusion coefficient of drug in the stratum corneum $\left(\mathrm{m}^{2} \cdot \mathrm{s}^{1}\right)$

$\mathrm{D}_{\mathrm{vs}} \quad$ Diffusion coefficient of drug in the viable skin $\left(\mathrm{m}^{2} . \mathrm{s}^{1}\right)$

$\mathrm{H} \quad$ Thickness of the skin after microneedles have been inserted $(\mu \mathrm{m})$

$\mathrm{H}_{\text {eff }} \quad$ Effective skin thickness of the skin after microneedles have been inserted $(\mu \mathrm{m})$

$\mathrm{H}_{\mathrm{sc}} \quad$ Thickness of the stratum corneum $(\mu \mathrm{m})$

$\mathrm{H}_{\mathrm{vs}} \quad$ Thickness of the viable skin $(\mu \mathrm{m})$

$\mathrm{h} \quad$ Thickness of the epidermis $(\mu \mathrm{m})$

$\mathrm{J} \quad$ Flux of drug through the skin (units. $\mathrm{m}^{-2} \cdot \mathrm{s}^{-1}$ )

$\mathrm{J}_{\mathrm{ss}} \quad$ Steady-state diffusion flux (units. $\mathrm{m}^{-2} \cdot \mathrm{s}^{-1}$ )

$\mathrm{L} \quad$ Microneedle length $(\mu \mathrm{m})$

$\mathrm{L}_{\mathrm{u}} \quad$ Uncoated microneedle length $(\mu \mathrm{m})$

$\mathrm{P} \quad$ Drug permeability in skin $\left(\mu \mathrm{m} \cdot \mathrm{s}^{-1}\right)$

$\mathrm{P}_{\text {eff }} \quad$ Effective permeability of the skin when coated microneedles are being used $\left(\mu \mathrm{m} \cdot \mathrm{s}^{-1}\right)$

$\mathrm{P}_{\text {skin }} \quad$ Skin permeability $\left(\mu \mathrm{m} . \mathrm{s}^{-1}\right)$

$\mathrm{R}_{\mathrm{D}} \quad$ The ratio of diffusion coefficients in the viable skin and stratum corneum (-)

$\mathrm{R}_{\mathrm{p}} \quad$ The ratio of drug permeability with microneedles to the permeability of normal skin (without microneedles) (-)

S The width and length of the square element of skin $(\mu \mathrm{m})$

t Time (s)

$\mathrm{x} \quad$ The distance in a given skin layer $(\mu \mathrm{m})$ 


\section{References}

Al-Qallaf, B., Das, D.B., Mori, D. and Cui, Z.F., 2007, Modelling transdermal delivery of high molecular weight drugs from microneedle systems, Journal of Phil. Trans. R. Soc. A., 365: 2951-2967.

Al-Qallaf, B. and Das, D.B., 2007, Optimizing microneedle arrays to increase skin permeability for transdermal drug delivery. Submitted for review and publication. In: Proceedings of Interdisciplinary Transport Phenomena V (ITP2007): Fluid, Thermal, Biological, Materials and Space Sciences, October 12-19, Bansko, Bulgaria.

Badkar, A.V., Smith, A.M., Eppstein, J.A. and Banga, A.K., 2007, Transdermal delivery of interferon alpha-2B using microporation and iontophoresis in hairless rats, Pharmaceutical Research, 24(7): 1389-1395.

Choi, J.W., Park, I.B., Ha, Y.M., Jung, M.G., Lee, S.W. and Lee, S.H., 2006, Insertion force estimation of various microneedle array-type structures fabricated by a 550 Microstereolithography Apparatus, In: Proceedings of International Joint Conference, October 18-21, Bexco, Pusan, Korea.

Comsol, AB, 2005, FEMLAB ${ }^{\circledR} 3$ multiphysics modelling, Documentation, Comsol AB., Stockholm, Sweden.

Cormier, M., Johnson, B., Ameri, M., Nyam, K., Libiran, L., Zhang, D.D. and Daddona, P., 2004, Transdermal delivery of desmopressin using a coated microneedle array patch system, Journal of Controlled Release, 97: 503-511.

Davis, S.P., Landis, B.J., Adams, Z.H., Allen, M.G. and Prausnitz, M.R., 2004, Insertion of microneedles into skin: measurement and prediction of insertion force and needle fracture force, Journal of Biomechanics, 37: 1155-1163.

Gill, H.S. and Prausnitz, M.R., 2007, Coated microneedles for transdermal delivery, Journal of Controlled Release, 117: 227-237.

Haider, I., Pettis, R.J., Davison, N., Clarke, R. and Zahn, J.D., 2001, Biomedical and fluid flow characterization of microneedle-based drug delivery devices, In: Proceedings of the 25th 
Annual Meeting of the American Society of Biomechanics, August, San Diego, California, 570 USA (Abstract).

Henry, S., McAllister, D.V., Allen, M.G. and Prausnitz, M.R., 1998, Microfabrication microneedles: A novel approach to transdermal drug delivery, J. Pharm. Sci., 87(8): 922-925.

Hsu, C.C., Chen, Y.T., Tsai, C.H. and Kang, S.W., 2007, Fabrication of microneedles, In: Proceedings of the $2^{\text {nd }}$ IEEE International Conference on Nano/Micro Engineered and Molecular Systems, January 16-19, Bangkok, Thailand.

Ito, Y., Hagiwara, E., Saeki, A., Sugioka, N. and Takada, K., 2006, Feasibility of 580 microneedles for percutaneous absorption of insulin, European Journal of Pharmaceutical Science, 29: 82-88.

Khumpuang, S., Horade, M., Fujioka K. \& Sugiyama, S., 2005, Through-hole microneedle fabricated by alignment x-ray lithography, Memoirs of the SR Center Ritsumeikan University, 585 No. 7, April, pp.25-30, Japan.

Khumpuang, S., Horade, M., Fujioka K., Kazuya, F. and Sugiyama, S., 2007, Geometrical strengthening and tip-sharpening of a microneedle array fabricated by X-ray lithography, Microsyste. Technol., 13: 209-214.

Kim, K. and Lee, J.B., 2007, High aspect ratio tapered hollow metallic microneedle arrays with microfluidic interconnector, Microsyst. Technol., 13: 231-235.

Kumar, R. and Philip, A., 2007, Modified transdermal technologies: breaking the barriers of drug permeation via the skin, Tropical Journal of Pharmaceutical Research, 6(1): 633-644.

Lv, Y.G., Liu, J., Gao, Y.H. and Xu, B., 2006, Modelling of transdermal drug delivery with a microneedle array, Journal of Micromechanics and Microengineering, 16: 2492-2501

Martanto, W., Davis, S.P., Holiday, N.R., Wang, J., Gill, H.S. and Prausnitz, M.R., 2004, Transdermal Delivery of Insulin Using Microneedles in Vivo, Pharmaceutical Research, 21: 947-952. 
Matriano, J.A., Cormier, M., Johnson, J., Young, W.A., Buttery, M., Nyam, K. and Daddona, 605 P.E., 2002, Macroflux microprojection array patch technology: a new and efficient approach for intracutaneous immunization, Pharmaceutical Research, 19(1): 63-70.

McAllister, D.V., Wang, P.M., Davis, S.P., Park J.H., Canatella, P.J., Allen, M.G. and Prausnitz, M.R., 2003, Microfabricated needles for transdermal delivery of macromolecules 610 and nanoparticles: fabrication methods and transport studies, PNAS, 100: 13755-13760.

Merino, G., Kalia, Y.N. and Guy, R.H., 2003, Ultrasound enhanced transdermal transport, $J$. Pharm. Sci., 92: 1125-1137.

Mitragotri, S., Blankschtein, D. and Langer, R., 1995, Ultrasound-mediated transdermal protein delivery, Science, 269: 850-853.

Ovsianikov, A. and Chichkov, B., 2007, Two photon polymerization of polymer-ceramic hybrid materials for transdermal drug delivery, International Journal of Applied Ceramic 620 Technology, 4(1): 22-29.

Park, J.H., Allen, M.G. and Prausnitz, M.R., 2005, Biodegradable polymer microneedles: Fabrication, mechanics and transdermal drug delivery, Journal of Controlled Release, 104: 51-66.

Park, J.H., Yoon, Y.K., Choi, S.O., Prausnitz, M.R. and Allen, M.G., 2007, Tapered conical polymer microneedles fabricated using an integrated lens technique for transdermal drug delivery, IEEE Transactions on Biomedical Engineering, 54(5): 903-913.

Parker, E.R., Rao, M.P., Turner, K.L., Meinhart, C.D. and MacDonald, N.C., 2007, Bulk micromachined titanium microneedles, Journal of Microelectromechanical Systems, 16(2): 289-295.

Prausnitz, M.R., 2004, Microneedles for transdermal drug delivery, Advanced Drug Delivery Reviews, 56: 581-587.

Rajaraman, S. and Henderson, H.T., 2005, A unique fabrication approach for microneedles using coherent porous silicon technology, Sensors and Actuators B, 105: 443-448. 
Rodriquez, A., Molinero, D., Valera, E., Trifonov, T., Marsal, L.F., Pallares, J. and Alcubilla, R., 2005, Fabrication of silicon oxide microneedles from macroporous silicon, Sensors and Actuators B, 109: 135-140.

Sen, A., Daly, M.E. and Hui, S.W., 2002, Transdermal insulin delivery using lipid enhanced 645 electroporation, Biochim. Biophys. Acta, 1564: 5-8.

Sintov, A.C. and Wormser, U., 2007, Topical iodine facilitates transdermal delivery of insulin. Journal of Controlled Release, 118: 185-188.

Stoeber, B. and Liepmann, D., 2005, Arrays of hollow out-of-plane microneedles for drug delivery, J. Microelect. Systems, 14(3): 472-479.

Tao, S.L. and Desai, T.A., 2003, Microfabricated drug delivery systems: from particles to pores, Advanced Drug Delivery Reviews, 55: 315-328.

Teo, M.A.L., Shearwood, C., Ng, K.C., Lu, J. and Moochhala, S., 2005, In Vitro and In Vivo Characterization of MEMS Microneedles, Biomedical Microdevices, 7(1): 47-52.

Teo, M.A.L., Shearwood, C., Ng, K.C., Lu, J. and Moochhala, S., 2006, Transdermal 660 microneedles for drug delivery applications, Materials Science and Engineering, 132: 151154.

Tojo, K., 1987, Mathematical modelling of transdermal drug delivery, Journal of Chemical Engineering in Japan, 20: 300-308.

Tojo, K., 2005, Mathematical models of transdermal and topical drug delivery, 2nd ed., (Biocom Systems Inc., Japan).

Wang, P.M., Cornwell, M., Hill, J., Prausnitz, M.R., 2006, Precise Microinjection into Skin 670 Using Hollow Microneedles, Journal of Investigative Dermatology, 126: 1080-1087.

Wilke, N., Reed, M.L. and Morrissey, A., 2006, The evolution from convex corner undercut towards microneedle formation: theory and experimental verification, J. Micromech. Microeng, 16: 808-814. 
Wilke, N. and Morrissey, A., 2007, Silicon microneedle formation using modified mask designs based on convex corner undercut, J. Micromech. Microeng., 17: 238-244.

Williams, A.C., and Barry, B.W., 2004, Penetration enhancers, Adv. Drug Deliv. Rev., 56: 680 603-618.

Widera, G., Johnson, J., Kim, L., Libiran, L., Nyam, K., Daddona, P. and Cormier, M., 2006, Effect of delivery parameters on immunization to ovalbumin following intracutaneous administration by a coated microneedle array patch system, Vaccine, 24: 1653-1664

Wu, X.M., Todo, H. and Sugibayashi, K., 2006, Effects of pretreatment of needle puncture and sandpaper abrasion on the in Vitro skin permeation of fluorescein isothiocyanate (FITC)dextran, International Journal of Pharmaceutics, 316: 102-108.

Wu, X.M., Todo, H. and Sugibayashi, K., 2007, Enhancement of skin permeation of high molecular compounds by a combination of microneedle pretreatment and iontophoresis, Journal of Controlled Release, 118: 189-195.

Xie, Y., Xu, B. and Gao, Y., 2005, Controlled transdermal delivery of model drug compounds by MEMS microneedle array, Nanomedicine: Nanotechnology, Biology and Medicine, 1: 184-190. 
Table 1. The design parameters of each microneedle model.

\begin{tabular}{|c|c|c|c|c|c|c|c|}
\hline Model & Figure No. & Penetration depth $(\mu \mathrm{m})$ & Diameter/Width & Microneedle thickness $(\mu \mathrm{m})$ & Center-to-center spacing $(\mu \mathrm{m})$ & Coating depth $(\mu \mathrm{m})$ & Number in array \\
\hline A & $2 \mathrm{~A}$ & 140 & 50 & N/A & 100 & 100 & 200 \\
\hline B & 2B & 140 & 50 (at base) & N/A & 100 & 100 & 200 \\
\hline $\mathrm{C}$ & $2 \mathrm{C}$ & 140 & 50 & N/A & 100 & 100 & 200 \\
\hline $\mathrm{D}$ & $2 \mathrm{D}$ & 140 & 50 & 35 & 100 & 100 & 200 \\
\hline $\mathrm{E}$ & $2 \mathrm{E}$ & 140 & 30 (shaft) and 60(tip) & 35 & 100 & 100 & 200 \\
\hline $\mathrm{F}$ & $2 \mathrm{~F}$ & 140 & 50 & 35 & 100 & 100 & 200 \\
\hline
\end{tabular}




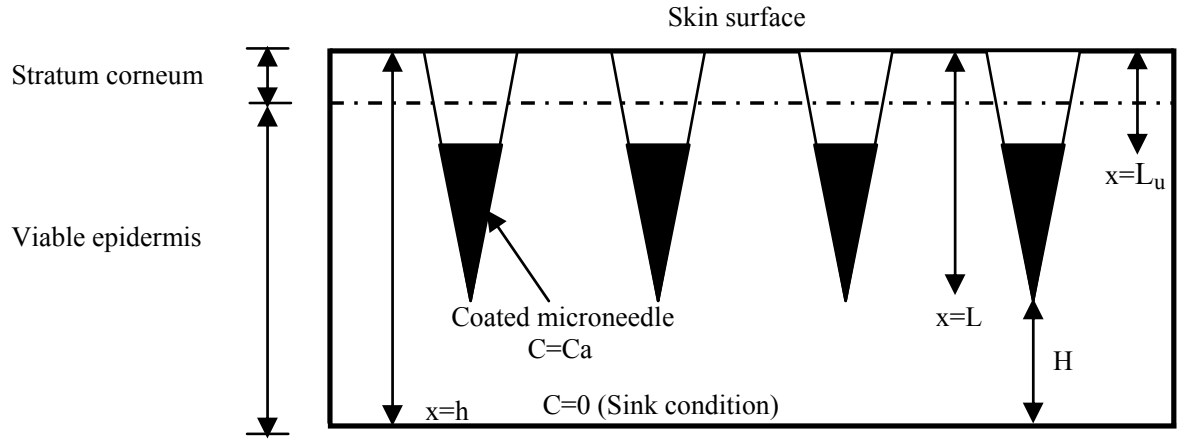

Figure 1. Schematic of coated microneedles for transdermal drug delivery. $\mathrm{L}_{u}$ is the uncoated microneedle length, $\mathrm{L}$ is the total microneedle length, $\mathrm{h}$ is the epidermis thickness and $\mathrm{H}$ is the thickness of the skin after microneedles have been inserted, i.e., the distance between microneedle tip and the blood micro-circulation. 

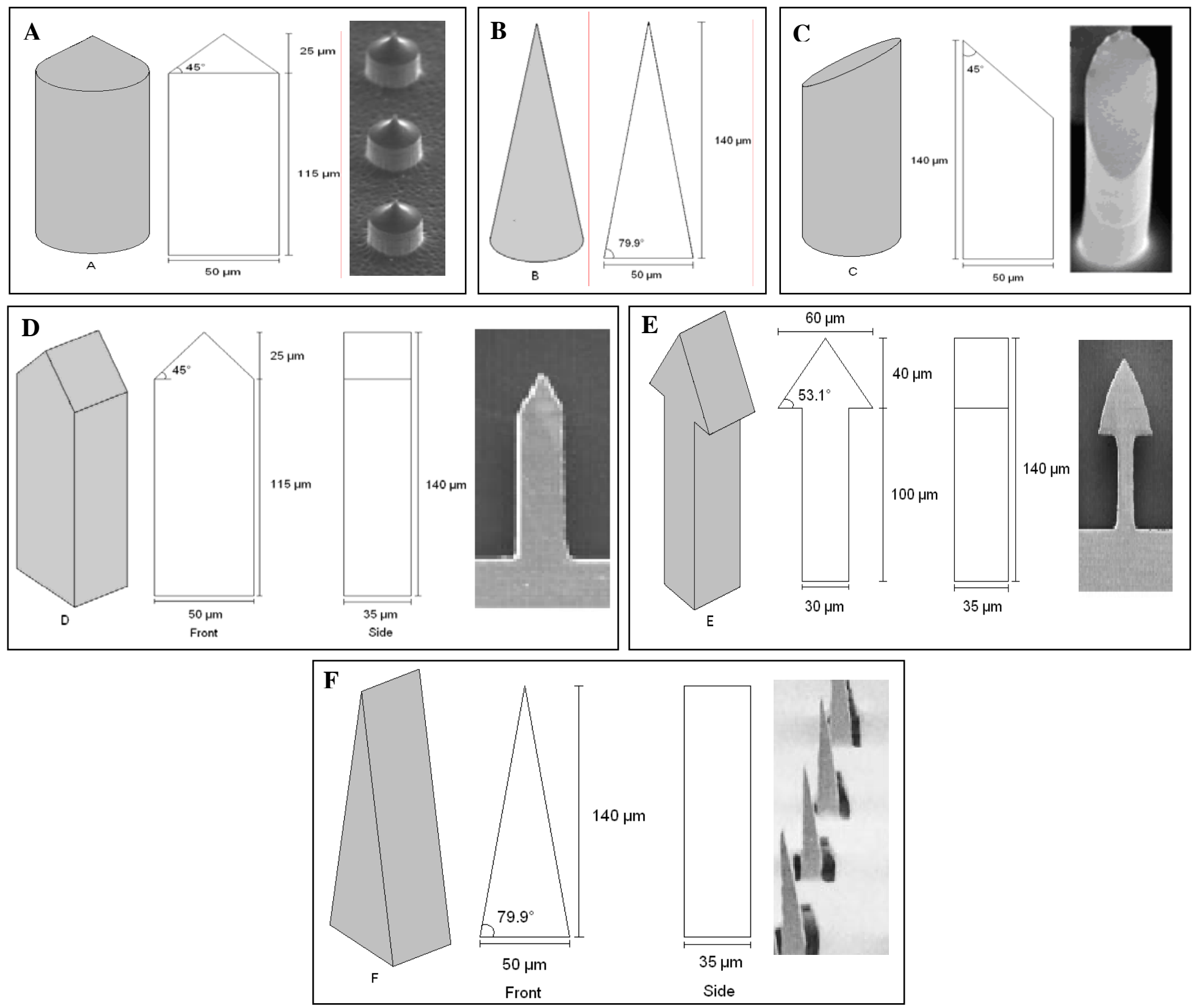

Figure 2. The different microneedles models used for coating drugs. (A) was fabricated by Xie et al. (2005), (B) was fabricated by Henry et al. (1998), (C) was proposed by McAllister et al. (2003), (D) \& (E) were fabricated by Gill and Prausnitz (2007) and (F) was fabricated by Martanto et al. (2004). 


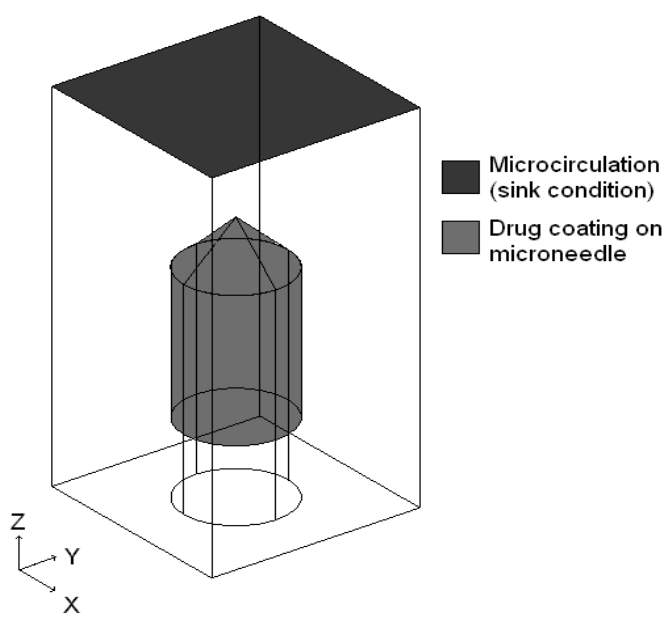

(a)

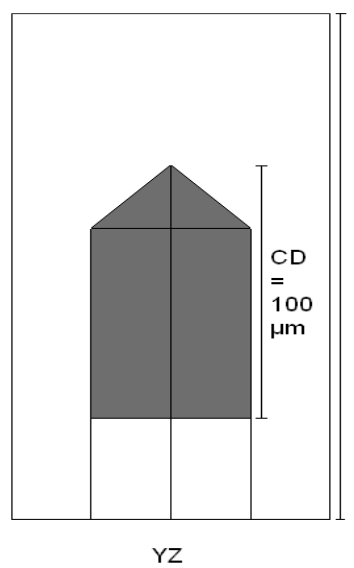

(b)

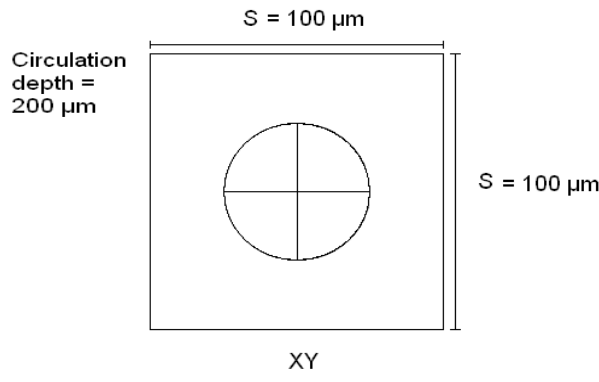

(c)

Figure 3. A schematic model for modelling diffusion from a microneedle through the skin: (a) $3 \mathrm{D}$ view, (b) side view and (c) top view. $\mathrm{CD}$ is the coating depth of drug on the microneedle and $\mathrm{S}$ is the width and length of the square element of skin. 


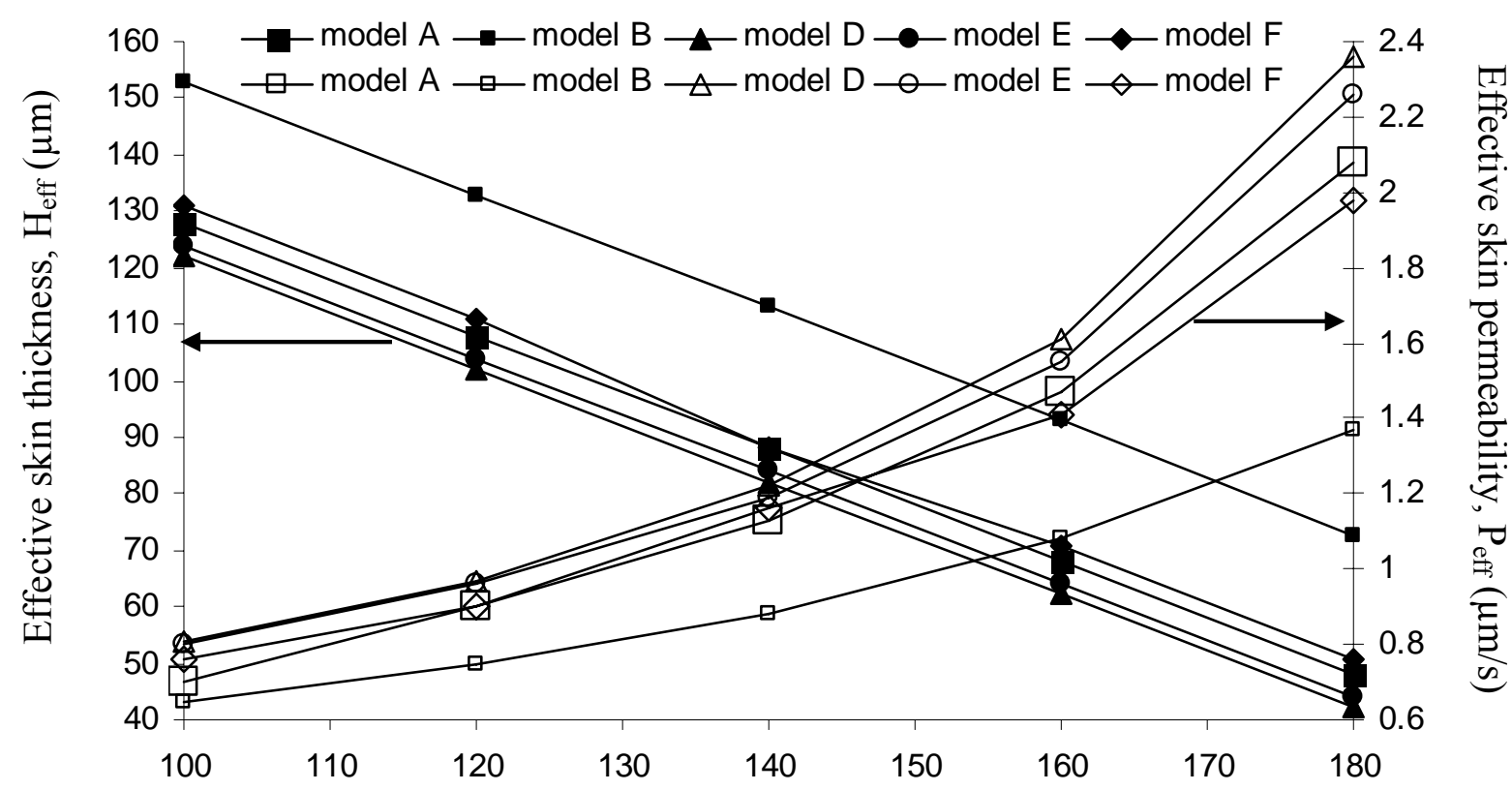

Penetration Depth $(\mu \mathrm{m})$

Figure 4. Influence of the changing penetration depth of various microneedles models, coated with insulin, on effective skin thickness $\mathrm{H}_{\text {eff }}$ (solid markers) and effective skin permeability $\mathrm{P}_{\text {eff }}$ (blank markers). 


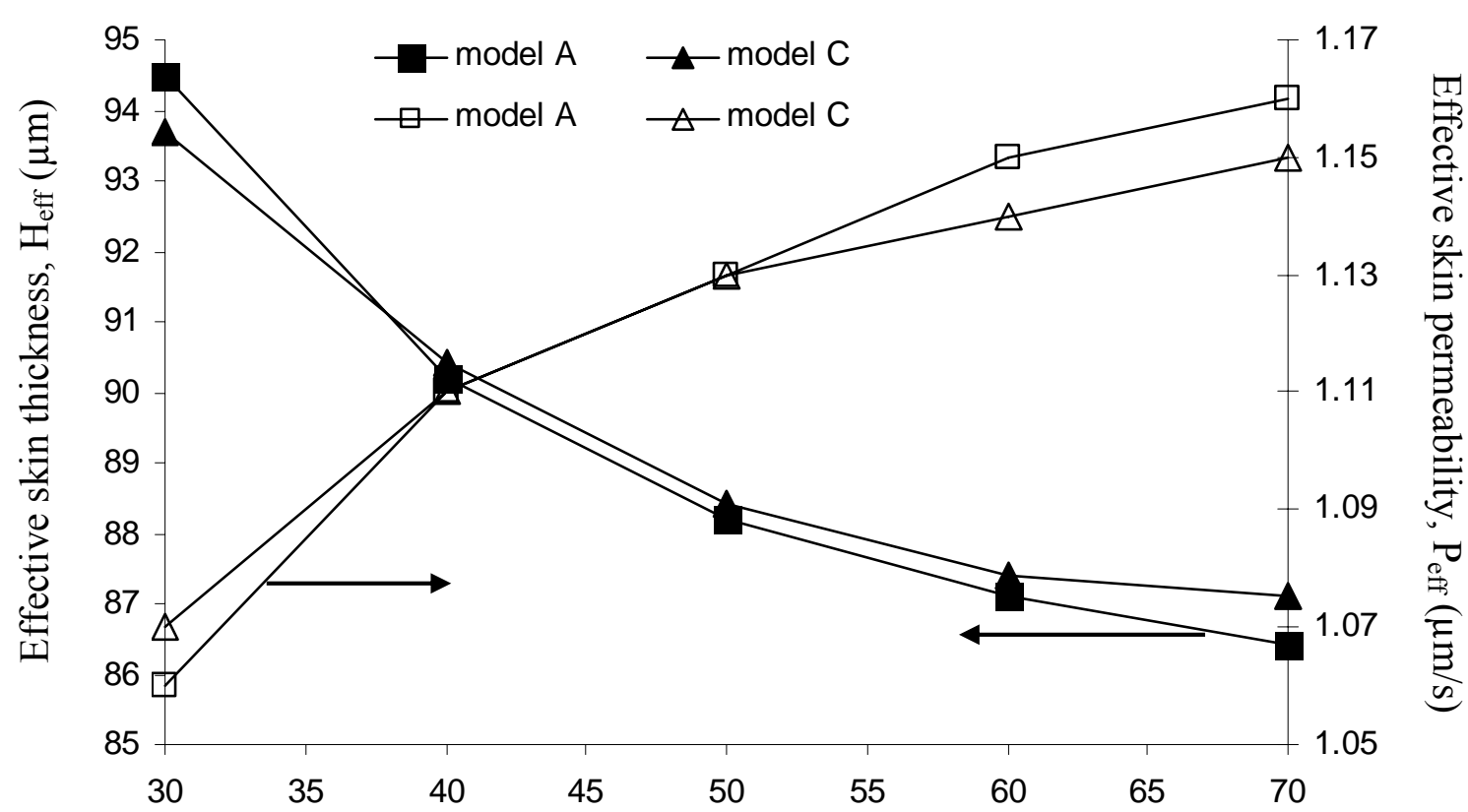

Microneedle Diameter $(\mu \mathrm{m})$

Figure 5. Influence of the microneedle diameter of insulin coated microneedles models on the effective skin thickness $\mathrm{H}_{\mathrm{eff}}$ (solid markers) and effective skin permeability $\mathrm{P}_{\mathrm{eff}}$ (blank markers). 


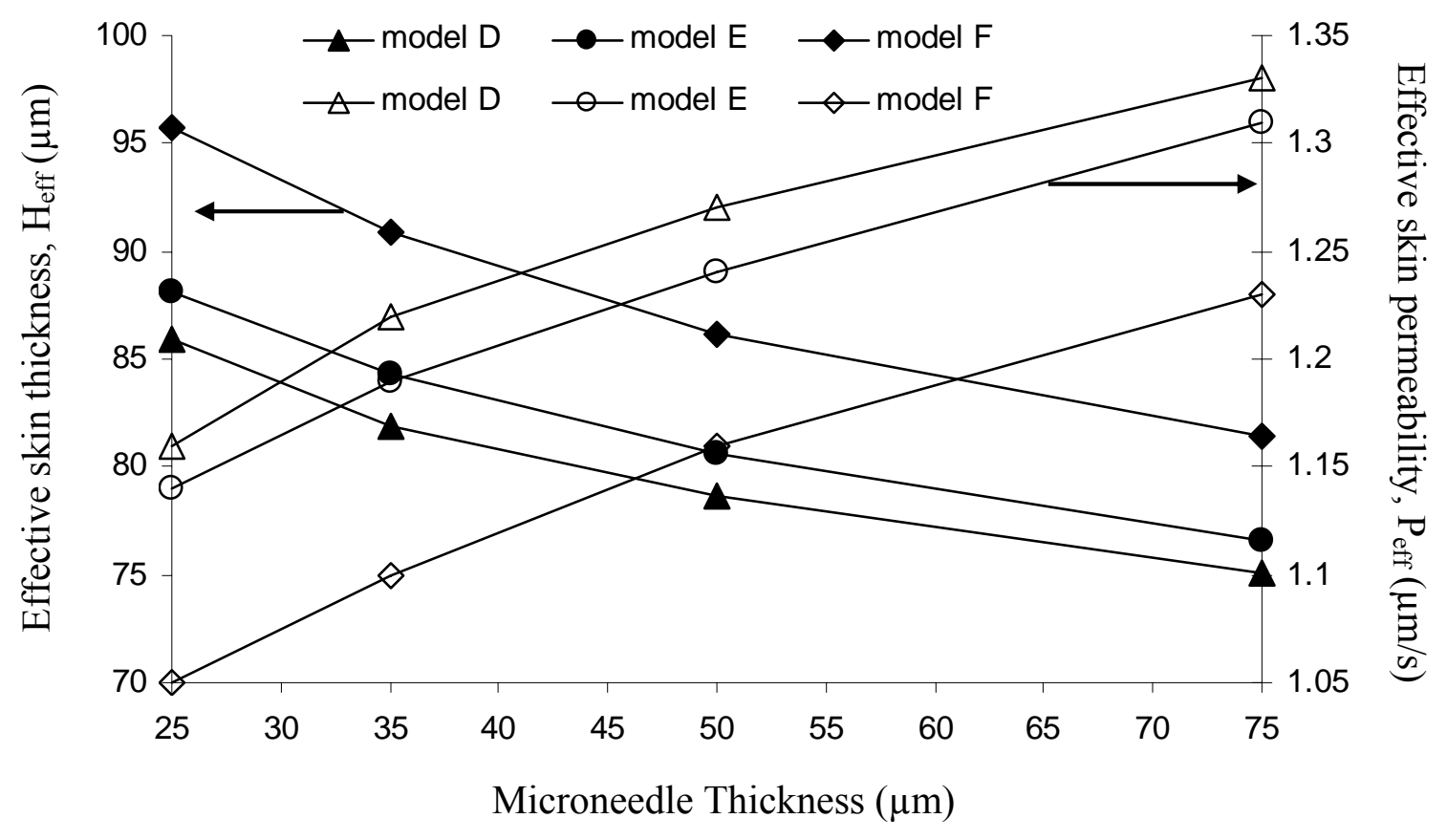

Figure 6. Influence of microneedle thickness of insulin coated microneedles models on effective skin thickness $\mathrm{H}_{\text {eff }}$ (solid markers) and effective skin permeability $\mathrm{P}_{\text {eff }}$ (blank markers). 


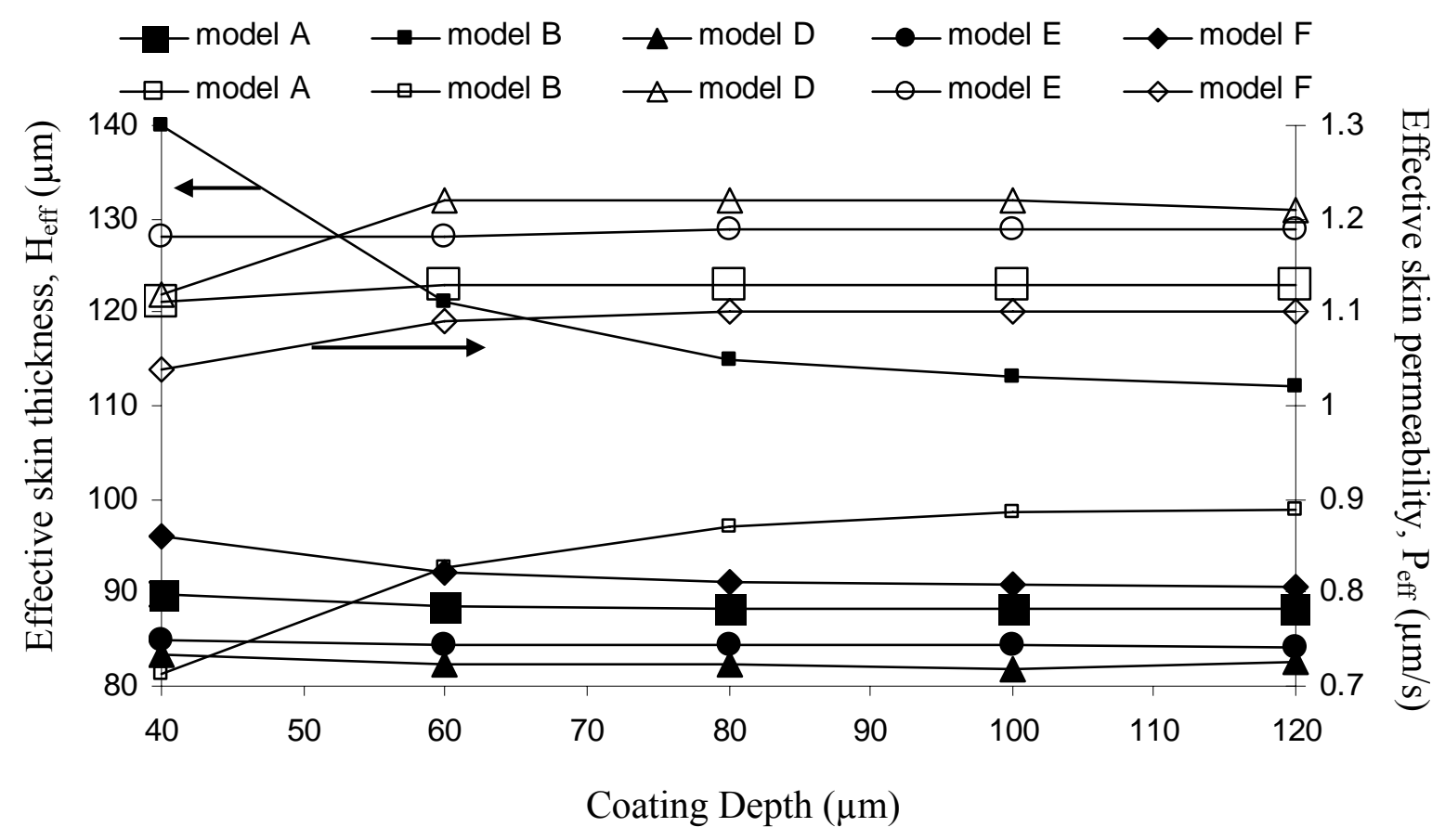

Figure 7. Influence of microneedle coating depth of insulin for various microneedles models on effective skin thickness $\mathrm{H}_{\text {eff }}$ (solid markers) and effective skin permeability $\mathrm{P}_{\text {eff }}$ (blank markers). 


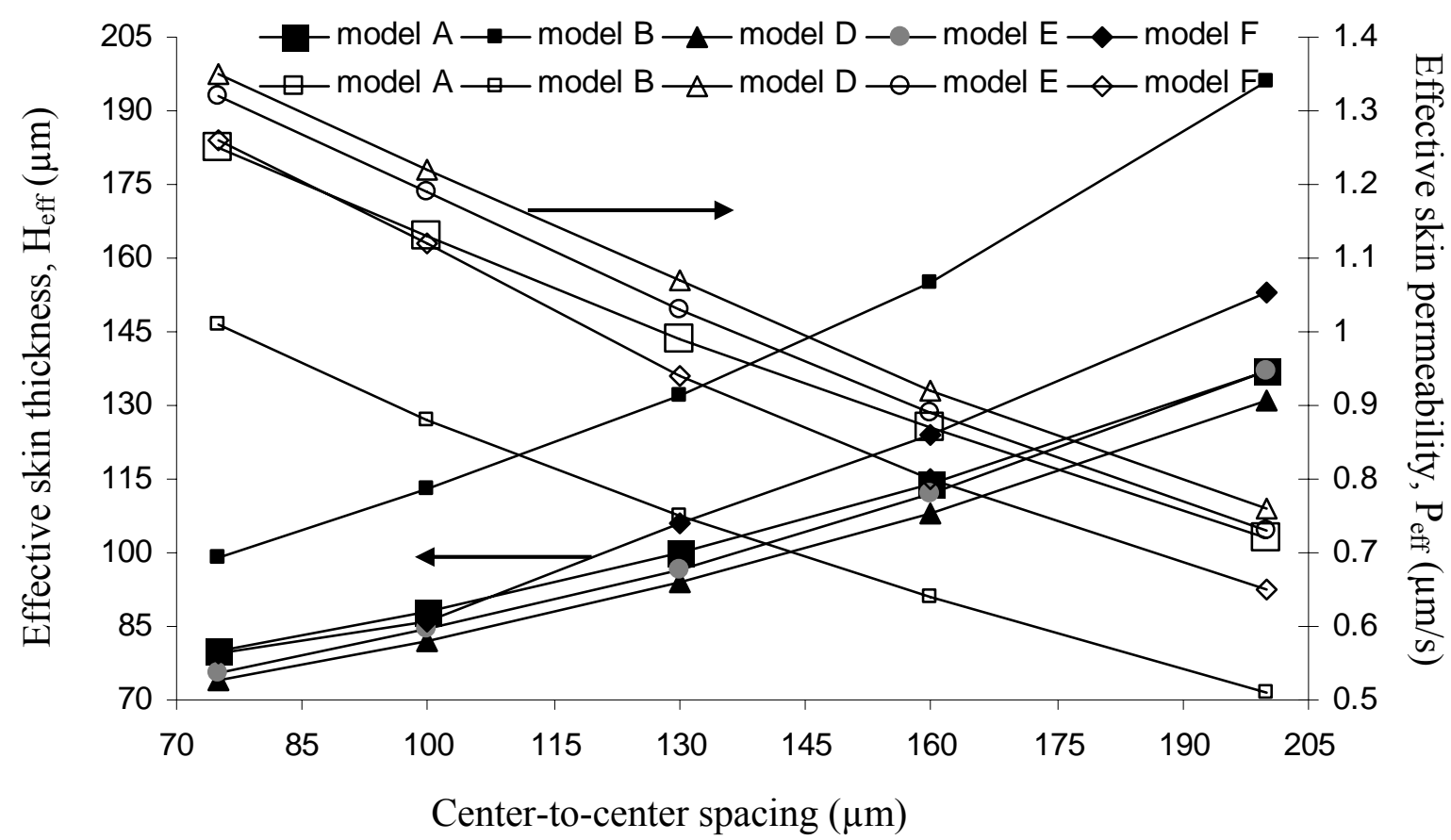

Figure 8. Influence of insulin coated micro-needle spacing on the effective skin thickness $\mathrm{H}_{\text {eff }}$ (solid markers) and effective skin permeability $P_{\text {eff }}$ (blank markers). 


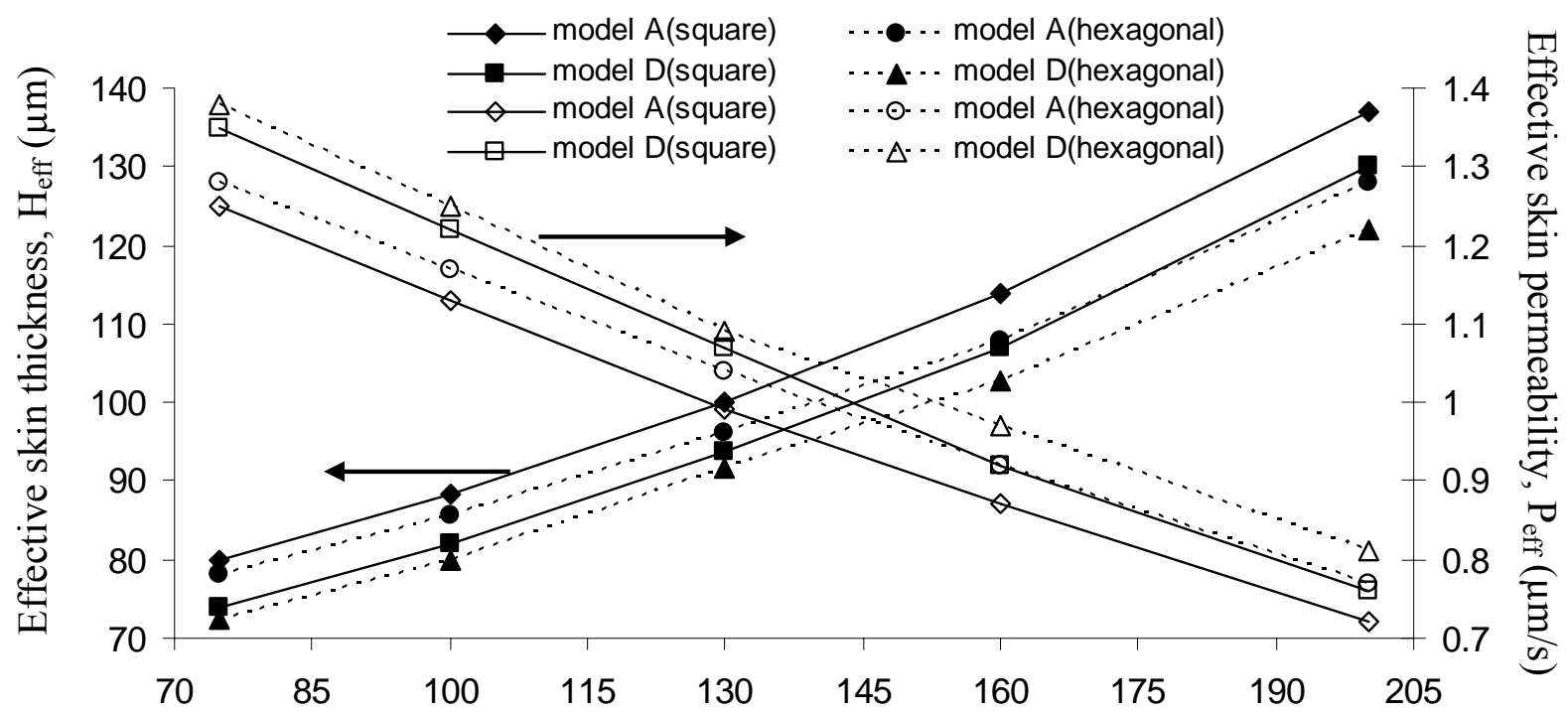

Center-to-center spacing $(\mu \mathrm{m})$

Figure 9. Comparison of the effects of insulin coated microneedle spacing for models A and D for square and hexagonal microneedle patterns on effective skin thickness $H_{\text {eff }}$ (solid markers) and effective skin permeability $\mathrm{P}_{\text {eff }}$ (blank markers). 


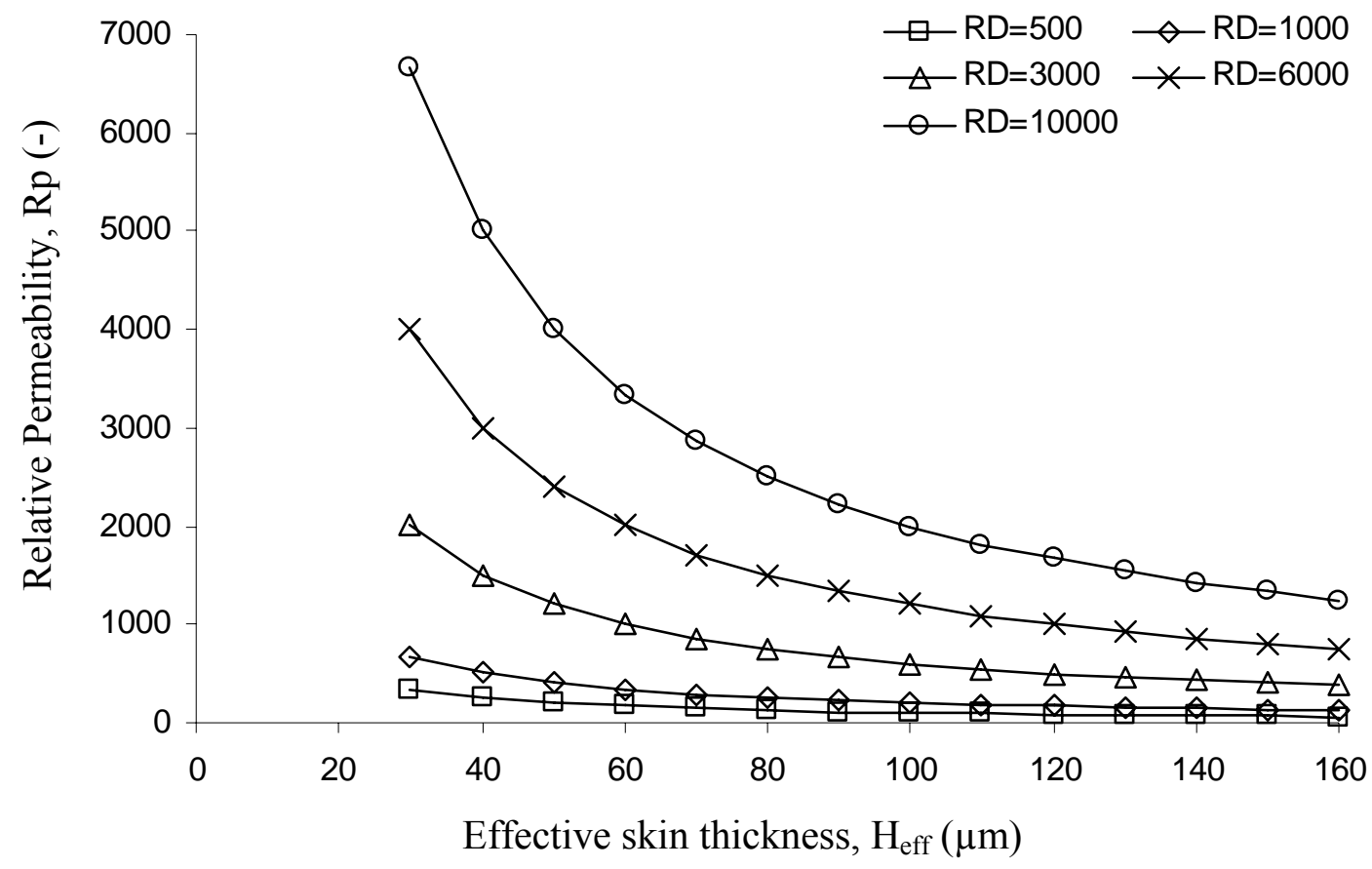

Figure 10. The relative permeability of treated skin to untreated skin $\left(\mathrm{R}_{\mathrm{p}}\right)$ as a function of the ratio of diffusion coefficients in the viable skin and stratum corneum $\left(\mathrm{R}_{\mathrm{D}}\right)$ and the effective skin thickness $\left(\mathrm{H}_{\text {eff }}\right) . \mathrm{Rp}(-)$ is the ratio of drug permeability with microneedles to the permeability of normal skin (i.e., without microneedles). 